\title{
Cortical Axon Guidance by the Glial Wedge during the Development of the Corpus Callosum
}

\author{
Tianzhi Shu and Linda J. Richards \\ The University of Maryland, Baltimore, School of Medicine, Department of Anatomy and Neurobiology, and the Program \\ in Neuroscience, Baltimore, Maryland 21201
}

Growing axons are often guided to their final destination by intermediate targets. In the developing spinal cord and optic nerve, specialized cells at the embryonic midline act as intermediate targets for guiding commissural axons. Here we investigate whether similar intermediate targets may play a role in guiding cortical axons in the developing brain. During the development of the corpus callosum, cortical axons from one cerebral hemisphere cross the midline to reach their targets in the opposite cortical hemisphere. We have identified two early differentiating populations of midline glial cells that may act as intermediate guideposts for callosal axons. The first differentiates directly below the corpus callosum forming a wedge shaped structure (the glial wedge) and the second differentiates directly above the corpus callosum within the indusium griseum.
Axons of the corpus callosum avoid both of these populations in vivo. This finding is recapitulated in vitro in three-dimensional collagen gels. In addition, experimental manipulations in organotypic slices show that callosal axons require the presence and correct orientation of these populations to turn toward the midline. We have also identified one possible candidate for this activity because both glial populations express the chemorepellent molecule slit-2, and cortical axons express the slit-2 receptors robo-1 and robo-2. Furthermore, slit-2 repels-suppresses cortical axon growth in three-dimensional collagen gel cocultures.

Key words: corpus callosum; axon guidance; glial wedge; cortex development; indusium griseum; slit-2; robo; chemorepulsion; midline
Developing neocortical axons exit one hemisphere either laterally via the internal capsule or medially via the corpus callosum. The internal capsule acts as an intermediate target for corticofugal axons by secreting the chemotropic molecule netrin-1 (Metin et al., 1997; Richards et al., 1997). However netrin-1 is not expressed within the direct pathway of the corpus callosum (Kennedy et al., 1994), although the cortical axons of the corpus callosum do express the netrin-1 receptor DCC (deleted in colorectal cancer) (Shu et al., 2000), and both netrin-1 and DCC mutant mice are acallosal (Serafini et al., 1996; Fazeli et al., 1997). Recently, a number of other molecules have been identified, which, when mutated in mice, result in an acallosal phenotype (Orioli et al., 1996; Qui et al., 1996; Dahme et al., 1997; Yoshida et al., 1997; Dattani et al., 1999). However, little is known about the critical developmental processes that such molecules might regulate and the guidance mechanisms required for the corpus callosum to form.

Previous studies have identified a population of cells at the cortical midline called the glial sling. The glial sling is glial fibrillary acidic protein (GFAP)-negative (in rodents) and mi-

Received Oct. 5, 2000; revised Jan. 25, 2001; accepted Jan. 30, 2001.

This work was supported by National Institutes of Health Grant NS37792. We thank Kimberly Valentino for excellent technical assistance. We are grateful to Drs. M. Tessier-Lavigne and K. Brose for supplying us with the slit-2 and robo-1 and -2 probes for in situ hybridization, as well as the slit-2 and PectagB control DNA for cell transfections, and Dr. A. Messing for making the GFAP-lacZ (nuclear-targeted) mice available through The Jackson Laboratory (Bar Harbor, ME). Drs. M. T. Shipley, F. L. Margolis, A. Keller, and G. J. Goodhill provided helpf ul comments on this manuscript.

Correspondence should be addressed to Dr. Linda J. Richards, The University of Maryland, Baltimore, School of Medicine, Department of Anatomy and Neurobiology, HSF 222, 685 West Baltimore Street, Baltimore, MD, 21201. E-mail: lrich001@umaryland.edu.

Copyright (c) 2001 Society for Neuroscience 0270-6474/01/212749-10\$15.00/0 grates from the lateral ventricular zone to underlie the developing corpus callosum (Silver et al., 1982). Both ablation and rescue experiments (Silver et al., 1982; Silver and Ogawa, 1983) have shown that the glial sling is required for the development of the corpus callosum. Because the glial sling is not fully formed until relatively late in callosal development [at embryonic day (E) 17 in mouse] and other midline glial populations are important for the development of commissural pathways in other regions of the brain (Marcus et al., 1995; Cummings et al., 1997), we investigated the possibility that additional midline glial populations direct axons across the corpus callosum.

In Drosophila, midline glia determine which axons cross the midline and which axons remain ipsilateral (Jacobs and Goodman, 1989; Kidd et al., 1999). This guidance function is mediated by a slit (ligand)-roundabout (receptor) interaction (Kidd et al., 1999). Axons expressing roundabout are repelled by slit, which is expressed by midline glial cells (Kidd et al., 1998a,b, 1999; Rothberg et al., 1990). A third molecule, commissureless, also secreted by the midline glia, downregulates the expression of roundabout and allows axons to cross the midline because they no longer respond to slit (Tear et al., 1996; Kidd et al., 1998b, 1999). Recently, the vertebrate homologs of slit and roundabout (robo in vertebrates) were cloned and shown in vitro to repel motor, olfactory, hippocampal, and retinal axons and neuronal cell bodies (Ba-Charvet et al., 1999; Brose et al., 1999; Hu, 1999; Li et al., 1999; Wu et al., 1999; Zhu et al., 1999; Erskine et al., 2000; Niclou et al., 2000; Ringstedt et al., 2000). Given that slit-2 is expressed in the septum (Ba-Charvet et al., 1999; Li et al., 1999), a midline forebrain structure, we investigated whether slit-2 was expressed by the glial wedge and whether it could act as a chemorepellent for cortical axons during the period of callosal development. 

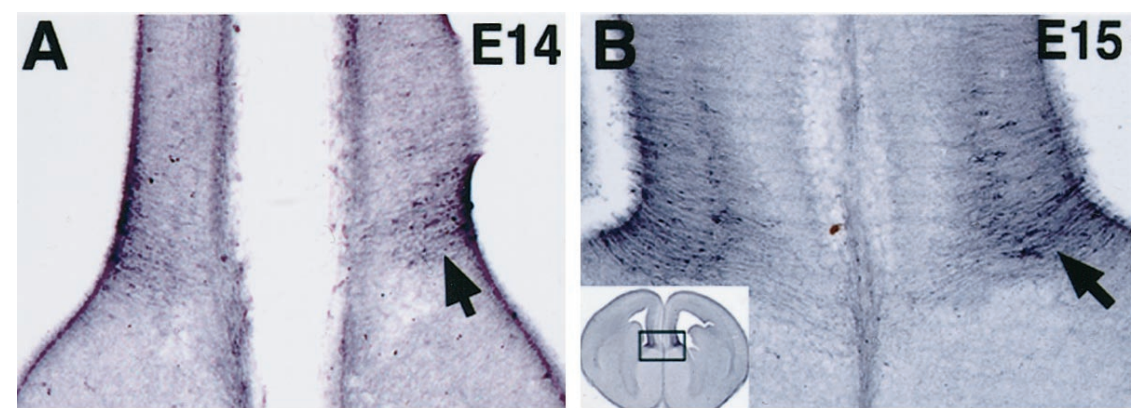

Figure 1. Development of midline glia and the corpus callosum. GFAP-positive cells are present by E14 in mouse cortex (arrow in $A$ ). These glia send long radialglial-like processes toward the midline, coalescing into a wedge-shaped structure by E15 (arrow in B). By E17, a second midline glial population arises in the indusium griseum (arrowhead in $C$ ), and the glial wedge is still present (arrow in $C$ ). At $\mathrm{P} 0$, both the indusium griseum glia (arrowhead in $D$ ) and the glial wedge (arrow in $D$ ) are present, but the glial wedge remains confined to the ventricular zone of the corticoseptal boundary. Staining of the GFAP-lacZ (nuclear-targeted) mice with an antibody to $\beta$-galactosidase shows that the cell bodies of the glial wedge remain within the ventricular-subventricular zone (arrow in $E$ ). F, Double-labeling of the glial wedge (arrow) and the indusium griseum glia (arrowhead) with GFAP antibody (green) and the callosal axons with DiI (red) show that the callosal axons do not enter these glial structures but pass between them. Scale bars: (in $D) A, B$ $150 \mu \mathrm{m} ; C, D, 240 \mu \mathrm{m}$; (in $F) E, 100 \mu \mathrm{m} ; F, 200 \mu \mathrm{m}$.
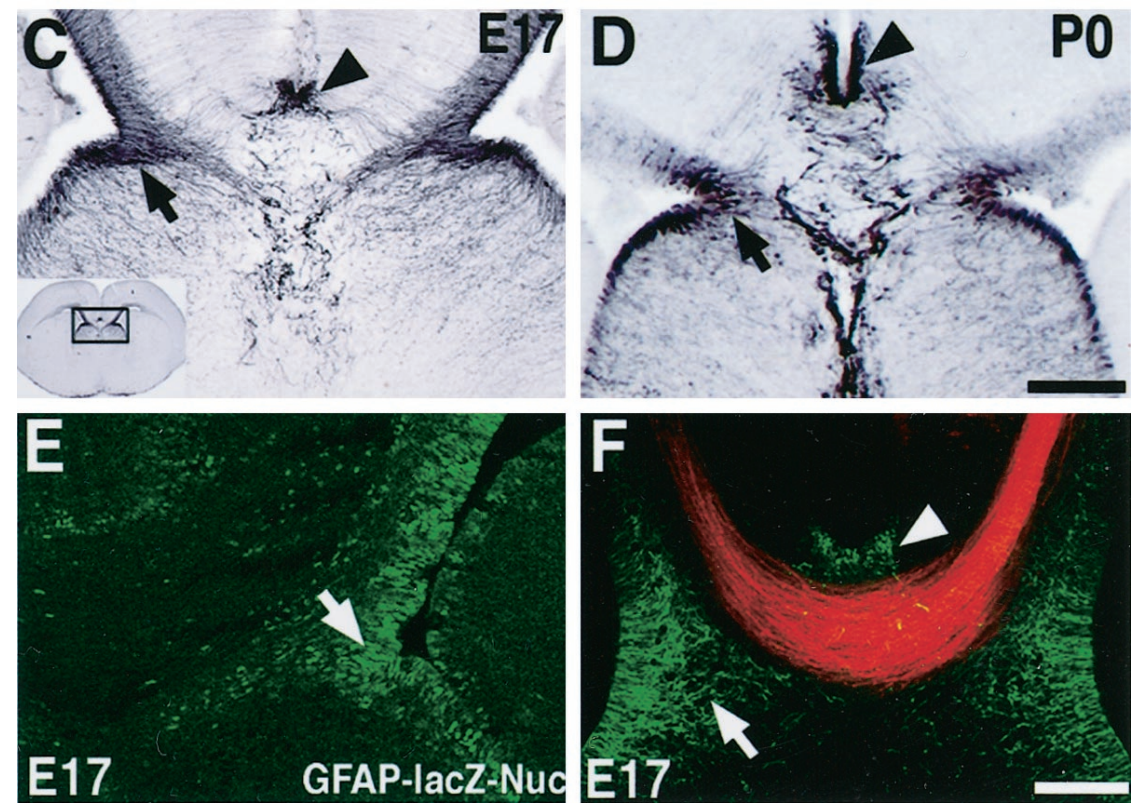

Parts of this work have been published previously in abstract form (Shu and Richards, 1999; Richards and Shu, 2000).

\section{MATERIALS AND METHODS}

Immunohistochemistry. Immunohistochemistry was performed as described previously (Shu et al., 2000). Primary antibodies used were as follows: (1) rabbit anti-cow GFAP (Dako, Daco, Denmark ), 1: 30,000 for nickel-DAB reaction and 1:1000 for fluorescent Cy2 detection, and (2) rabbit anti-Escherichia coli $\beta$-galactosidase (5 Prime $\rightarrow 3$ Prime Inc., Boulder, CO), 1:2000 for fluorescent Cy2 detection. Secondary antibodies used were as follows: (1) biotinylated goat anti-rabbit (Vector Laboratories, Burlingame, CA), 1:600, and (2) Cy2-conjugated goat antirabbit IgG (Jackson ImmunoResearch, West Grove, PA), 1:400.

In situ hybridization. In situ hybridization was performed as described previously (Tuttle et al., 1999) on cryostat sections with the addition of dextran sulfate (Sigma, St. Louis, MO) at a concentration of $300 \mu l / 1.5$ $\mathrm{ml}$ total volume in the both the prehybridization and hybridization steps. For Slit-2-GFAP double-labeling, GFAP immunohistochemistry was performed first as described above, followed by the in situ hybridization with two changes: (1) the proteinase $\mathrm{K}$ concentration was reduced to 1 $\mu \mathrm{g} / \mu \mathrm{l}$, and (2) the permeabilization step with DEPC-PBS-Triton X-100 was eliminated.

DiI labeling. Small injections of a $10 \%$ solution of DiI (Molecular Probes, Eugene, OR) in dimethylformamide were made using pulled glass pipettes attached to a Picospritzer (General Valve, Fairfield, NJ). Brains were stored in the dark at room temperature for at least 4 weeks to allow DiI transport and then vibratome-sectioned at $45 \mu \mathrm{m}$. GFAP immunohistochemistry was performed as described above but without the addition of Triton X-100.

Dissection and culture of explants and transfected cells. Living E17 C57BL/6J mouse brains were blocked in 3\% low melting point agar (Sea plaque; FMC Bioproducts, Rockland, ME) and vibratome-sectioned at $350 \mu \mathrm{m}$. Explants of cortex and glial wedge were dissected from the regions shown in Figure $2 A$ and cocultured in collagen gels (Collabora- tive Research, Bedford, MA) as described previously (Richards et al., 1997). Collagen gels were cultured in DMEM-F12 medium (Life Technologies, Gaithersburg, MD) supplemented with $1 \%$ penicillinstreptomycin, $0.28 \%$ glucose, $1 \%$ of $200 \mathrm{~mm}$ glutamine, $5 \%$ rat serum, and $10 \%$ fetal bovine serum. After $3 \mathrm{~d}$, the cultures were fixed in $4 \%$ paraformaldehyde, and a $10 \%$ solution of DiI in dimethylformamide was injected into the cortical explants. Explants were kept in the dark at $37^{\circ} \mathrm{C}$ for at least $48 \mathrm{hr}$ to allow for DiI diffusion. slit-2-expressing cells were prepared by transfecting $10 \mu \mathrm{g}$ of recombinant human slit2 DNA or PectagB vector control DNA [a gift from Dr. M. Tessier-Lavigne and Dr. K. Brose (both from University of California, San Francisco, San Francisco, CA)] using LipofectAMINE PLUS reagent (Life Technologies) following a standard protocol. Cell blocks were prepared as described previously (Richards et al., 1997). To quantify the axonal length and number, the mean axon length was derived by measuring the length of the 10 longest axons on each side of the explant. The number of all axons on the proximal side versus the other three sides of the explants were counted. To quantify axon repulsion, we counted the number of axons that grew out straight initially and then turned away from the Slit-2expressing cells at an angle of at least $30^{\circ}$. Percentages of axons repelled were derived from the number of axons repelled on the proximal side divided by the total number of axons on the proximal side, pooled over all of the explants in one group.

Organotypic slice cultures. Organotypic slices were prepared from living E17 C57BL/6J mouse brains, vibratome-sectioned at $350 \mu \mathrm{m}$. Coronal slices were cultured on $30 \mathrm{~mm}$ culture plate inserts (Millipore, Bedford, MA) coated with $10 \mu \mathrm{g} / \mathrm{ml}$ poly-L-lysine (Sigma) and $2 \mu \mathrm{g} / \mathrm{ml}$ laminin (Becton Dickinson, Cockeysville, MD), in six-well tissue culture plates. Experimental dissections and manipulations (see schematics in Fig. 3) were performed using a $1 \mathrm{~mm}$ blade especially made for these experiments. Slices were cultured in DMEM-F12 medium with $1 \%$ penicillin-streptomycin, $0.28 \%$ glucose, $1 \%$ of $200 \mathrm{~mm}$ glutamine, $5 \%$ rat serum, $10 \% \mathrm{FBS}$, and $10 \mathrm{ng} / \mathrm{ml}$ mouse nerve growth factor $(2.5 \mathrm{~S}$; Alomone Labs, Jerusalem, Israel). After $3 \mathrm{~d}$ in culture, the slices were 

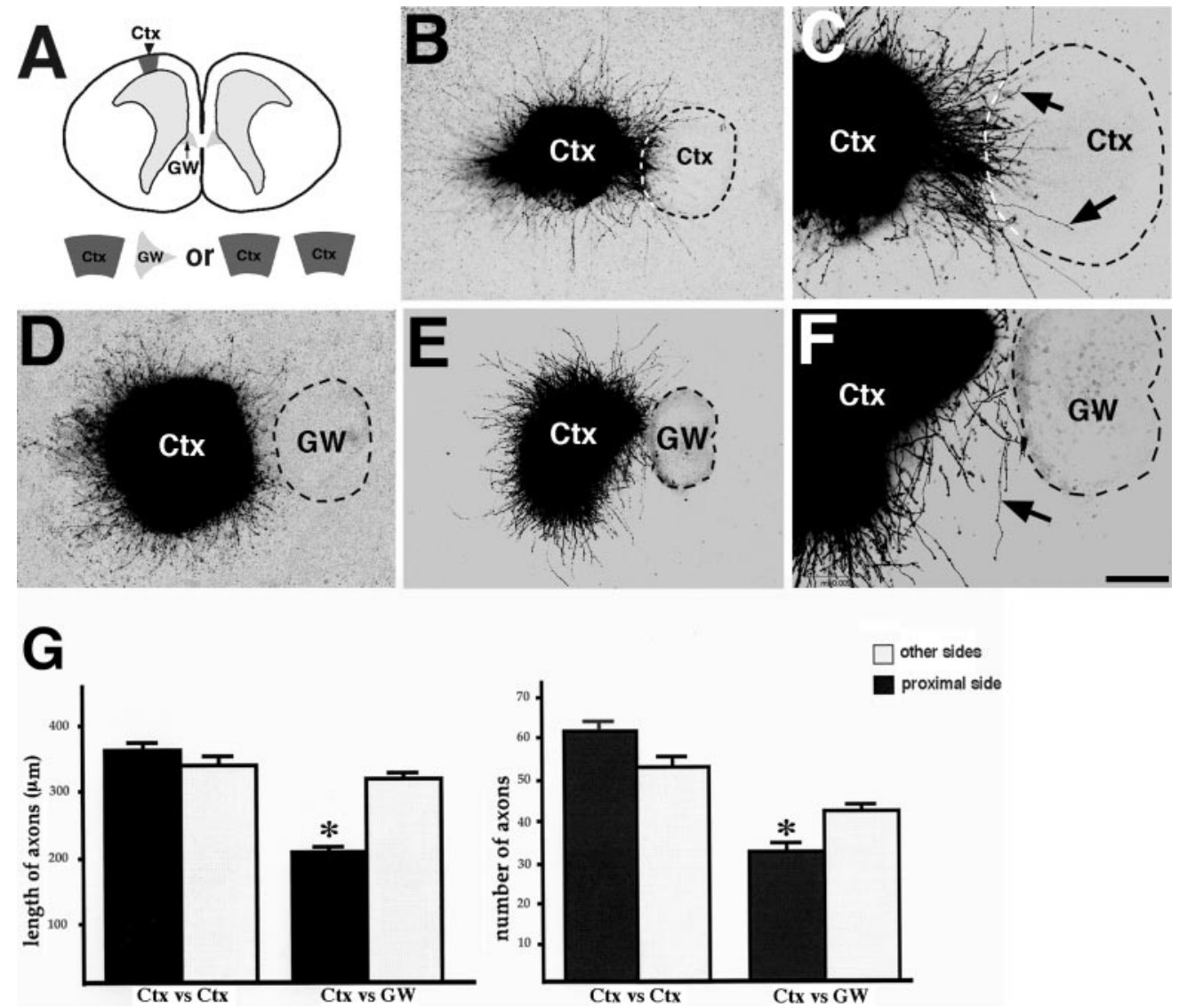

Figure 2. The glial wedge suppresses and repels E17 cortical axons. $A$, Schematic of the experimental paradigm. Cortical explants $(C t x)$ and glial wedge explants $(G W)$ were dissected from coronal sections ( $350 \mu \mathrm{m}$ in thickness) of E17 mouse brain. Cortical explants were cocultured with either glial wedge explants $(D-F)$ or with other cortical explants $(B, C)$ in three-dimensional collagen gels. After $3 \mathrm{~d}$, the cultures were fixed, and DiI was injected into the cortical explant. When cortex was paired with cortex as a control, the cortical axons projected symmetrically from the explant $(B)$, growing into the target cortical explant (arrow in $C$; $C$ is a higher power view of $B$ ). When cortex was paired with glial wedge, the length of axons on the proximal side facing the glial wedge was greatly diminished $(D-F)$, with many axons turning away (arrow in $F$ ) or stopping at the edge of the glial wedge explant $(D$ and $E$ are two different examples; $F$ is a higher power view of $E$ ). $G$, Quantification of axonal length (mean axon length was derived by measuring the length of the 10 longest axons on each side of the explant) and number on the proximal side versus the other three sides of the explants. Statistically significant results are labeled (*). Scale bar (in $F$ ): $B, D, F, 300 \mu \mathrm{m} ; C, F, 150 \mu \mathrm{m}$.

fixed in $4 \%$ paraformaldehyde and then either resectioned at $50 \mu \mathrm{m}$ for GFAP immunohistochemistry or a DiI crystal (Molecular Probes) was inserted into the cortical plate. Seventy-two hours was allowed for DiI diffusion before the slices were mounted in polyvinyl alcohol-1,4diazabicyclo-[2.2.2]octane mounting medium for confocal microscopy.

\section{RESULTS}

\section{Development of midline glial populations at the corticoseptal boundary}

Although GFAP-positive glia were previously thought to arise late in embryonic development (Valentino et al., 1983), more recent reports described GFAP mRNA expression at E15 in rats (Sancho-Tello et al., 1995) and the expression of a reporter transgene under the control of the GFAP promoter at E13.5 in the mouse cortex (Brenner et al., 1994). To investigate the possibility that glial populations may arise early at the cortical midline, we performed a time course of GFAP expression in early embryonic brains. We found two early differentiating populations of midline glial cells. The first differentiates at the dorsomedial aspect of the lateral ventricles at E14, sending long radial processes toward the midline (Fig. $1 A$ ). By E15, these radial processes coalesce into a wedge-shaped structure on either side of the midline (Fig. 1B), which remains evident at both E17 and post- natal day $0(\mathrm{P} 0)$ (Fig. $1 C, D$, arrows). We term this structure the "glial wedge." Rostrocaudally, the glial wedge is present from the taenia tecta to the hippocampal commissure (a distance of $\sim 500$ $\mu \mathrm{m}$ at E17). At the hippocampal commissure, glia can be seen inserting between the corpus callosum and the hippocampal commissure, although the wedge shape is lost in this region. We used a GFAP-lacZ transgenic mouse (Brenner et al., 1994) in which the lacZ was targeted to the nucleus to investigate where the glial wedge cell bodies were located. These cell bodies are located within the ventricular zone (Fig. $1 E$ ), in contrast to the glial sling cells, which migrate toward the midline (Silver et al., 1982). The second glial population differentiates directly above the corpus callosum in the indusium griseum (Fig. 1C,D,F, arrowheads). These three midline glial structures (the glial sling, the glial wedge, and the indusium griseum glia) may coordinate midline cortical axon guidance.

The glial wedge and the indusium griseum glia form a restricted zone within which ventrally projecting callosal axons grow (Fig. $1 F$ ). The shape of the glial wedge suggests that it may act to deflect the cortical axons medially toward the midline. By labeling cortical axons with DiI and the glial wedge-indusium griseum glia with GFAP, we found that cortical axons make a 
Table 1. Quantification of process outgrowth from cortical explants

\begin{tabular}{|c|c|c|c|c|c|}
\hline \multirow[b]{2}{*}{ Experiment } & \multicolumn{2}{|c|}{$\underline{\text { Mean } \pm \text { SE length of axons }(\mu \mathrm{m})}$} & \multicolumn{2}{|c|}{ Mean \pm SE number of axons } & \multirow{2}{*}{$\begin{array}{l}\text { Total number of ex- } \\
\text { plants/total number of } \\
\text { experiments }\end{array}$} \\
\hline & $\begin{array}{l}\text { Proximal } \\
\text { side }\end{array}$ & $\begin{array}{l}\text { Other } 3 \text { sides } \\
\text { combined }\end{array}$ & $\begin{array}{l}\text { Proximal } \\
\text { side }\end{array}$ & $\begin{array}{l}\text { Other } 3 \text { sides } \\
\text { combined }\end{array}$ & \\
\hline Cortex vs cortex & $364 \pm 24$ & $341 \pm 27$ & $61 \pm 7$ & $52 \pm 7$ & $29 / 7$ \\
\hline Cortex vs glial wedge & $209 \pm 15^{*}$ & $311 \pm 14$ & $33 \pm 4^{*}$ & $41 \pm 3$ & $44 / 7$ \\
\hline $\begin{array}{l}\text { Cortex vs control } \\
\text { transfected cells }\end{array}$ & $428 \pm 21$ & $451 \pm 15$ & $89 \pm 8$ & $89 \pm 7$ & $38 / 4$ \\
\hline $\begin{array}{l}\text { Cortex vs Slit-2- } \\
\text { transfected cells }\end{array}$ & $234 \pm 19^{*}$ & $393 \pm 22$ & $22 \pm 3^{*}$ & $56 \pm 4$ & $51 / 4$ \\
\hline
\end{tabular}

${ }^{*} p<0.05$ indicates significant difference; Student's $t$ test.

sharp turn toward the midline when they encounter the glial wedge and extend medially in the channel formed by the glial wedge and the induseum griseum (Fig. $1 F$ ).

\section{The glial wedge suppresses-repels cortical axon growth}

To directly test whether these populations express an axonal guidance activity, we challenged axonal outgrowth from cortical explants with explants of glial wedge in three-dimensional collagen gels (Fig. 2A). Because the indusium griseum is so small, it was impossible to dissect this region specifically; therefore, the indusium griseum glia were excluded from this part of the analysis. As a control, cortical explants were also paired with a second cortical explant that did not exhibit guidance activity for cortical axons, as described previously (Richards et al., 1997). After 3 d in culture, DiI was injected into one cortical explant to label axon outgrowth. Because the glial wedge may express either diffusible or bound guidance signals, the distance between the explants may be critical to observing a response. The theoretical distance over which axons may be guided by target-derived diff usible signals is on the order of $1 \mathrm{~mm}$ (Goodhill, 1997). However, explants may need to be even closer to observe effects by bound or weakly diff usible molecules. Therefore, from the outset, only cultures in which the inter-explant distance was shorter than the longest axons on the proximal side of the explant were included in the analysis. In cortex-cortex cultures, axons extended radially from the explant (Fig. 2B, Table 1), growing into the control cortical explant in $96 \%$ of cases (Fig. $2 C$, arrows). In cortex-glial wedge cultures, axon length was generally shorter on the side of the explant facing the glial wedge (Fig. $2 D, G$ ). Those axons that did extend on the proximal side of the explant stopped at the edge of the glial wedge explant (Fig. $2 F$ ), growing into the glial wedge in only $12 \%$ of cases. We also observed many axons turning away from the glial wedge explant (Fig. $2 F$, arrow). In some explants, cortical axons were able to grow toward the glial wedge but did not enter the glial wedge, although in every case, the inter-explant distance was shorter than the length of the axons on the proximal side (Fig. 2E,F). These results suggest that the glial wedge expresses a membrane-bound or weakly diffusible molecule that inhibits cortical axons from growing into the glial wedge.

This asymmetric growth could be attributable to a decrease in axonal length or axonal number. Therefore, we quantified the length and number of axons projecting from the cortical explants in each of the conditions. In cortex-cortex cultures, the average length and number of axons on the proximal side was not significantly different from the other three sides combined (Fig. $2 G$, Table 1). In contrast, in cortex-glial wedge cultures, the mean axon length on the proximal side was significantly shorter than that of the other sides (Fig. 2D-G, Table 1), and we observed a small but significant difference in the mean number of axons on the proximal side versus the other sides $(p=0.03$ ) (Fig. $2 G$, Table 1). The effect on axon length was evident when the explants were $<300 \mu \mathrm{m}$ apart, again indicating that the glial wedge activity was likely to be a membrane-bound or weakly diff usible molecule.

\section{The glial wedge causes turning of callosal axons in situ}

Callosal axons leave the neocortex and travel ventrally under the subplate of the cingulate cortex. To cross the midline, they must reorient their growth cones by making a sharp turn medially just before crossing. The glial wedge directly underlies this axonal decision point. The axons contact the lateral part of the wedge and grow along it, turning sharply toward the midline. Therefore, both the shape and location of the glial wedge are well suited to direct cortical axons toward the midline and prevent them from entering the septum. In our previous collagen gel experiments, there was no way to determine whether the effect of the glial wedge was on subcortically (laterally) projecting or callosally (medially) projecting axons, because both populations were present in the explants.

To further investigate the ability of the glial wedge to direct medially projecting callosal axon growth, we developed an organotypic cortical slice preparation. Both the glial wedge (Fig. 3A) and the corpus callosum formed in these organotypic slices (Fig. $3 B, C)$. We hypothesized that reorienting the glial wedge might influence callosal axon pathfinding. Thus, the glial wedge was dissected out of slices, rotated $180^{\circ}$ (medial to lateral), and implanted back into the slice (Fig. $3 G-I$ ). Control slices were grown either intact or as sham-operated slices in which the glial wedge was dissected out and reimplanted without being rotated (Fig. 3D-F). All of the slices were cultured for $3 \mathrm{~d}$ and fixed, and a DiI crystal was inserted into the cortical plate to anterogradely label the callosal axons. Because the glial wedge sits in a notch of the lateral ventricle (also called the septal fork), we were able to identify the position of the glial wedge at the end of the experiment based on the shape of the tissue, the presence of the septal fork, and the cell density difference between the glial wedge and the cell-dense cingulate cortical plate. In both intact ( $n=11$ of 11 cases in six experiments) and sham-operated ( $n=8$ of 8 cases in eight experiments) slices, cortical axons extended normally, making an angular turn at the glial wedge and then crossing the midline (Fig. 3B-F). However, when callosal axons encountered the reoriented glial wedge graft, the axons turned away from the midline toward the lateral ventricle $(n=7$ of 7 cases in six experiments) (Fig. 3H,I).

In an additional experiment to confirm that the glial wedge was 

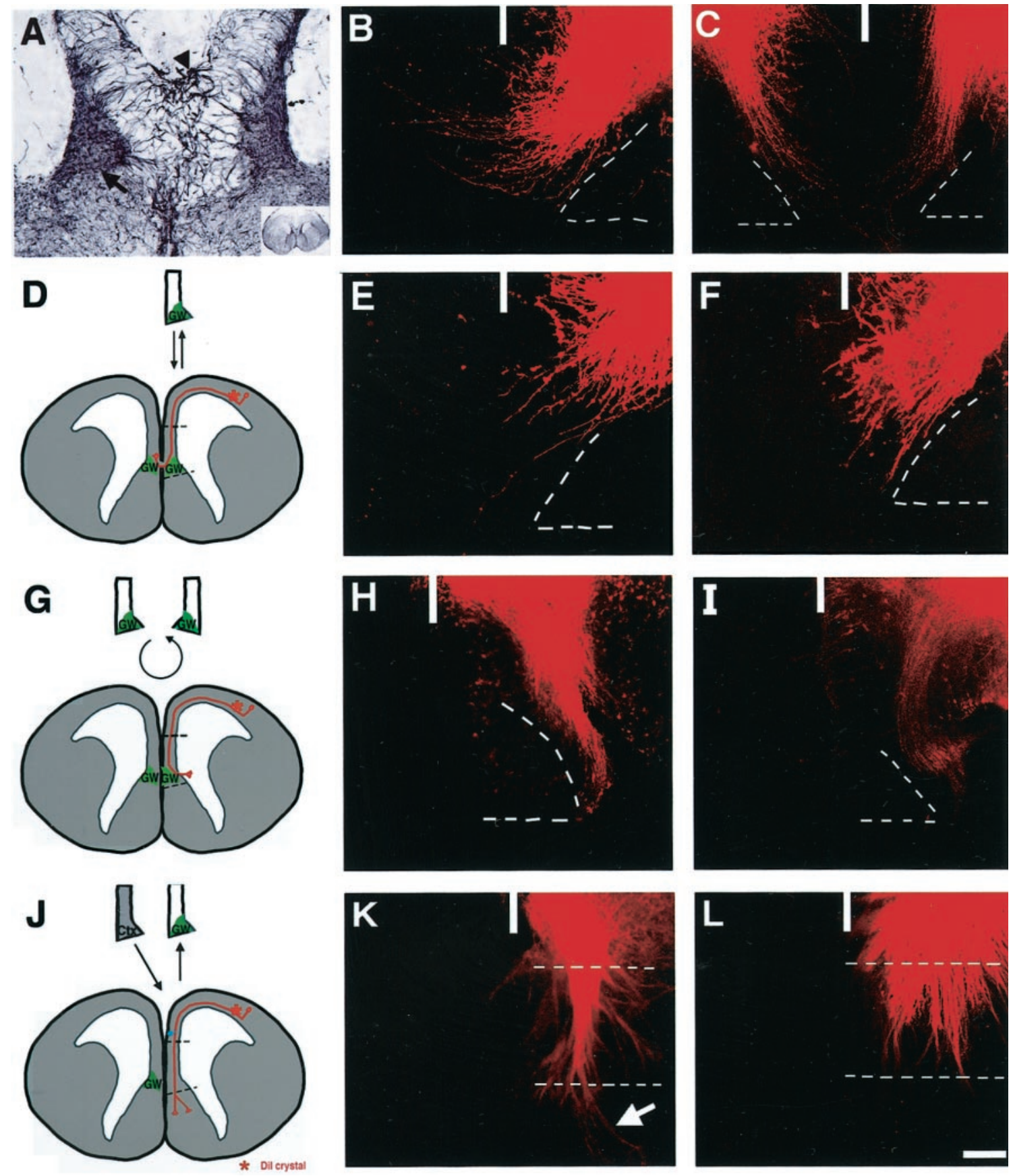

Figure 3. The glial wedge directs the growth of callosal axons in situ. A, The glial wedge forms in organotypic slices. E17 mouse brains were sectioned at $350 \mu \mathrm{m}$, grown for $3 \mathrm{~d}$ in culture, fixed, resectioned at $50 \mu \mathrm{m}$, and stained with a GFAP antibody. Both the glial wedge (arrow) and the indusium griseum glia (arrowhead) maintain their in vivo morphology after $3 \mathrm{~d}$ in vitro. $B, C$, The corpus callosum forms in organotypic slices. $B$ and $C$ represent two examples of uncut control slices, cultured for $3 \mathrm{~d}$ and fixed, and a crystal of DiI was added to label the callosal axons. In $C$, DiI crystals were placed on both sides of the midline to show that cortical axons from both hemispheres still cross in the same organotypic slice (in all other slices, DiI was added to only one hemisphere). $D-L$, Replacement or reorientation of the midline results in axonal misrouting. $D-F$, The corpus callosum forms normally in sham-operated slices ( $D$ shows the experimental paradigm, and $E$ and $F$ are two examples). $G-I$, Reorienting the glial wedge by $180^{\circ}$ causes the axons to turn away from the midline ( $G$ shows the experimental paradigm, and $H$ and $I$ are two examples). $J-L$, The glial wedge is required for axons to turn toward the midline. When the glial wedge-indusium griseum region is replaced on one side by a piece of cortex, cortical axons fail to turn and instead grow straight through the graft, in many cases entering the septum (arrow in $K ; J$ shows the experimental paradigm, and $K$ and $L$ are two examples). The white broken lines in $B, C, E, F, H$, and $I$ represent the position of the glial wedge; in $K$ and $L$, they represent the edges of the cortical graft. The solid white line in $B, C, E, F, H, I, K$, and $L$ represent the position of the midline. Scale bar (in $L$ ): $A, 120 \mu \mathrm{m} ; C, E, F, K, L, 200 \mu \mathrm{m} ; B, H, I, 100 \mu \mathrm{m}$.

required for cortical axons to turn toward the midline, we removed the glial wedge region and implanted a piece of cortex from another slice. Cortical tissue was used in this experiment because it did not contain significant numbers of GFAP-positive astrocytes at this developmental stage and because axons from cortical explants will grow within other cortical explants in collagen gels. In these experiments $(n=6$ of 6 cases in two experiments) (Fig. $3 J-L)$, axons grew straight into the grafts without 

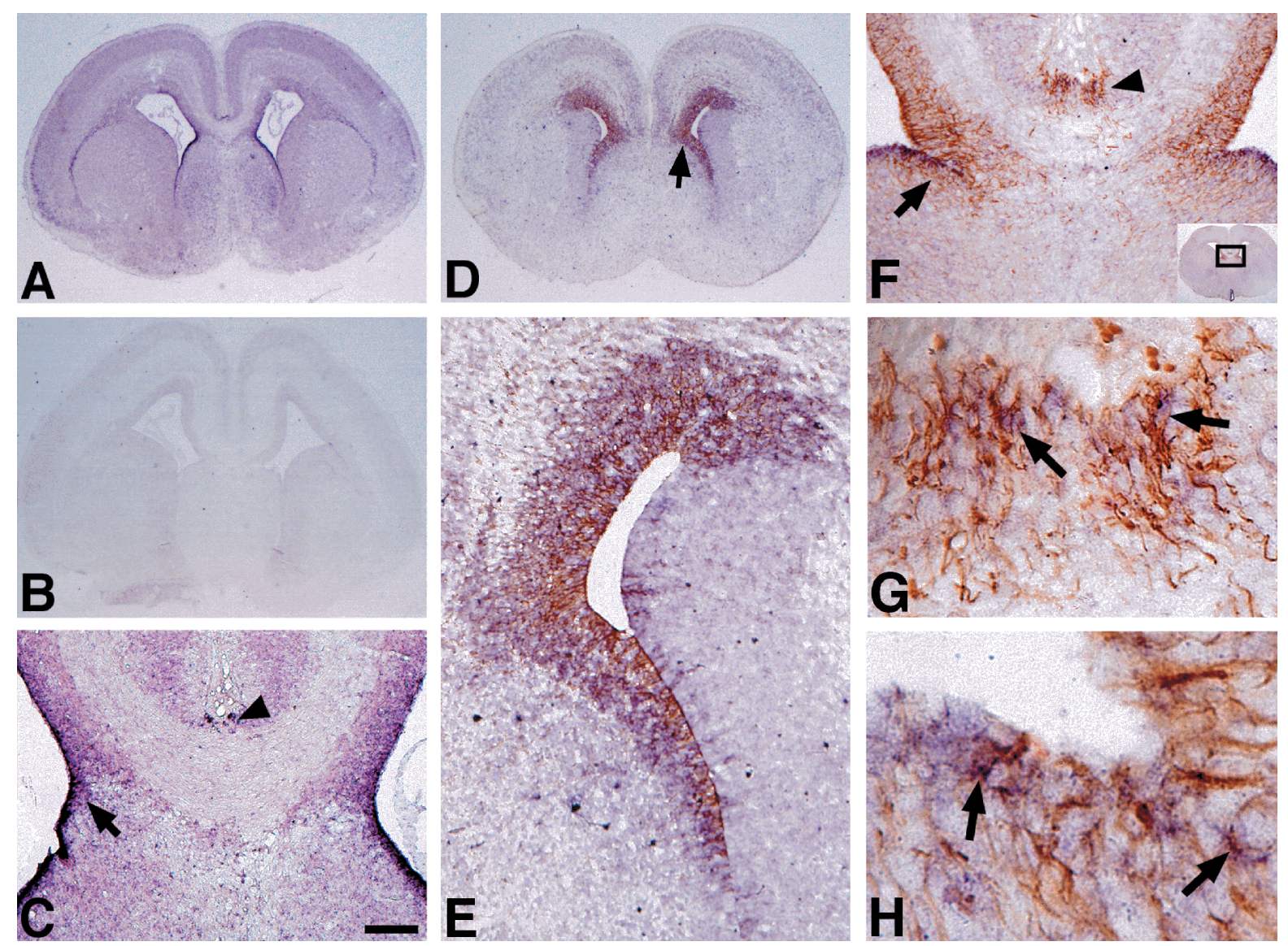

Figure 4. During callosal axon targeting, the glial wedge and the indusim griseum express slit-2. In situ hybridizations using slit-2 antisense $(A, C)$ probes show that slit-2 is expressed within the ventricular zone of the septum and corticoseptal boundary. The control slit-2 sense probe shows no specific labeling (B). slit-2 is expressed in both the glial wedge (arrow in $C$ ) and the indusium griseum glia (arrowhead in $C$; $C$ is a higher power view of $A$ ). $D, E$, Double-labeling of anti- $\beta$-galactosidase (driven by the GFAP promoter and targeted to the cytoplasm) immunohistochemistry and slit-2 in situ hybridization shows that cells within the glial wedge express both slit-2 and the lacZ transgene ( $E$ is a higher power view of $D$ ). In wild-type embryos, glia within the glial wedge (arrow in $F$ ) and the indusium griseum (arrowhead in $F$ ) are double-labeled with slit-2 (purple) and GFAP (brown). $F$ is a higher power view of the boxed region in the inset. Examples of double-labeled cells are shown in the indusium griseum (arrows in $G)$ and the glia wedge (arrows in $H ; G$ and $H$ are higher power views of $F$ ). All sections are from E17 mouse brains. Scale bar (in $C$ ): $A, B, D, 950 \mu \mathrm{m} ; C, 220 ; E, 110 \mu \mathrm{m} ; F$, $170 \mu \mathrm{m} ; G, 25 \mu \mathrm{m} ; H, 20 \mu \mathrm{m}$.

making a turn. In some cases, these axons grew through the cortical graft and into the septum (Fig. $3 K$, arrow). Together, these results indicate that both the presence and the correct orientation of the glial wedge are required for medially projecting callosal axons to turn toward the midline in situ.

\section{The glial wedge and indusium griseum glia express Slit-2}

In Drosophila, midline glia influence axon growth by expressing slit, which repels ipsilaterally projecting axons away from the midline (Jacobs and Goodman, 1989; Kidd et al., 1999). Because vertebrate Slit-2 also acts as membrane-bound weakly diff usible molecule (Brose et al., 1999) and is expressed in the septal fork of the lateral ventricle, a region corresponding to the glial wedge (Ba-Charvet et al., 1999; Li et al., 1999), slit-2 may be a glial wedge guidance signal. We first determined whether the glial wedge expressed slit-2 and whether the cortical neurons expressed robo. At E17, slit-2 mRNA was expressed in the medial subventricular zone along the lateral ventricles, in which the glial wedge cell bodies reside, and in the indusium griseum (Fig. 4A,C) but not in the glial sling. This expression was not observed in sections in which a slit-2 sense probe was used as a control (Fig. 4B). We also performed in situ hybridization using slit-2 antisense probes doubled with GFAP immunohistochemistry on tissue derived from both GFAP-lacZ (cytoplasmic targeted) transgenic mice (Fig. $4 D, E$ ) and C57BL/6J wild-type mice (Fig. $4 F-H$ ). In each case, slit-2 expression overlapped with GFAP expression (and lacZ expression), indicating that these glial populations do express slit-2 (Fig. 4D-H). Two other members of the slit family, slit-1 and slit-3, have not been shown to be expressed in the region corresponding to the glial wedge (Ba-Charvet et al., 1999; Yuan et al., 1999).

To respond to Slit-2, the cortical axons must express the slit-2 receptor robo. Using in situ hybridization, we found that both receptors of slit-2, robo-1 (Fig. 5A,C) and robo-2 (Fig. 5D,F), are highly expressed in cortical neurons at E17. Sections labeled with robo-1 sense (Fig. 5B) or robo-2 sense (Fig. 5E) probes showed no specific labeling. Therefore, the ligand, slit-2, is expressed in the glial wedge and the indusium grisuem glia, and the slit- 2 receptors robo- 1 and robo- 2 are expressed in the cortical neurons, at the appropriate time to mediate axon guidance at the midline.

\section{Slit-2 suppresses-repels cortical axon growth}

To test the hypothesis that Slit- 2 might be an axon guidance molecule expressed by the glial wedge-indusium griseum glia, we cultured cortical explants with agar blocks of 293T cells trans- 
Robo-1

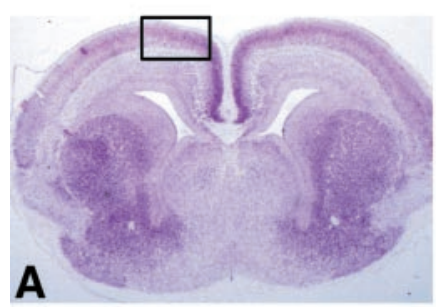

\section{B}

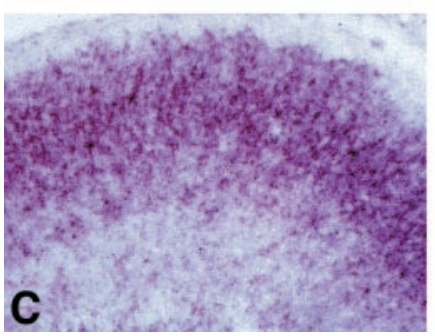

Robo-2

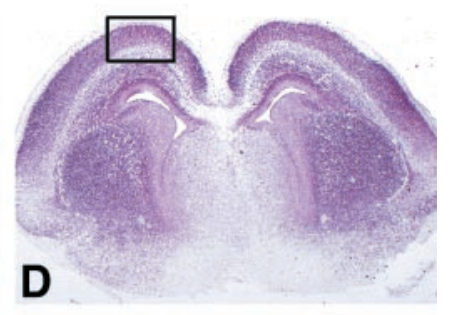

$\mathbf{E}$

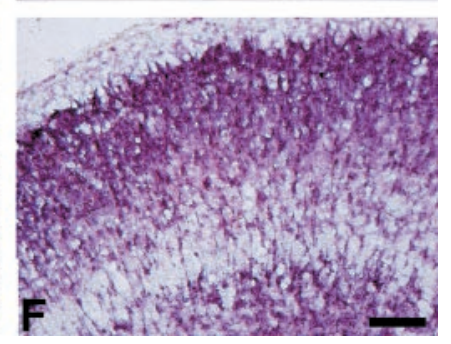

Figure 5. The slit-2 receptors robo-1 and robo-2 are expressed in the neocortex during callosal axon targeting. In situ hybridization using antisense probes against robo- $1(A, C)$ or robo-2 $(D, F)$ show that both receptors are expressed within the cortical plate at E17 ( $C$ and $F$ are higher power views of the boxed regions in $A$ and $D$, respectively). Control sense probes for either robo-1 $(B)$ or robo-2 $(E)$ show no specific labeling. Scale bar (in $F$ ): $A, B, D, E, 900 \mu \mathrm{m} ; C, F, 80 \mu \mathrm{m}$.

fected with either a Slit-2 expression construct or a control vector construct. The transfected cells were cocultured with E17 cortical explants in collagen gels, and DiI was again used to label the axon outgrowth. In controls, cortical axons projected radially (Fig. 6A) with axons growing into the cell block in $63 \%$ of cases (Fig. $6 D$, arrow; Table 1). There was also no significant difference in the mean number or length of axons on the proximal side versus the mean of the other three sides combined (Fig. 6G, Table 1). In explants cultured with Slit-2-expressing cells, axons preferentially grew away from the cell block with more axons exiting the explant on the side farthest from the Slit-2-expressing cells (Fig. 6B, C). In addition, significantly fewer axons extended toward the Slit-2expressing cells, and those that did were stunted in their growth (Fig. 6G, Table 1). Thus, many axons on the proximal side may have been repelled by Slit- 2 such that they did not even extend out of the explant, reflecting this decrease in axonal number on the proximal side. In addition, only $6 \%$ of these explants extended axons into the Slit-2-expressing $293 \mathrm{~T}$ cell block, and in most cases, the few axons that did reach the cell block grew along the edge of the cell block without growing into it (Fig. 6F, arrow). Furthermore, we observed a 10 -fold increase in the number of axons turning away from the Slit-2-expressing cells (Fig. 6E, arrow). Thus, Slit-2-expressing cells repelled cortical axons at a time when the callosal projection is forming.

\section{DISCUSSION}

We have shown that early midline glia do play a role in guiding axons at the midline during the formation of the corpus callosum.
We have identified the glial wedge and the indusium griseum glia as being important for this guidance. Both collagen gel and organotypic slice experiments show that the glial wedge expresses a guidance activity that causes callosal axons to turn toward the midline. The indusium griseum glia also express Slit-2 and therefore may participate in directing callosal axon growth. Indeed, in organotypic slice cultures, both the glial wedge and the indusium griseum were reoriented, indicating the importance of both populations. Previous reports described GFAP-positive glia in cats as important for midline fusion and radial glia (which may correspond to the glial wedge described here) as a lateral extension of the glial sling (Silver et al., 1993). However, our studies suggest that the glial wedge and the glial sling are independent populations. The glial wedge and the glial sling cells are born at different times and they express different cellular markers (including GFAP and Slit-2; our unpublished observations). Our working hypothesis is that these three populations, the glial wedge, the indusium griseum glia, and the sling, all participate in guiding callosal axons (Fig. 7). The glial wedge and indusium griseum glia participate by repelling callosal axons toward and across the midline through the actions of molecules, such as slit-2 and robo. The sling may participate by providing positive or attractive guidance cues, probably through a contact-mediated mechanism.

Midline glial populations have long been shown to be associated with the formation of commissures and boundaries between neuromeres (Levitt and Rakic, 1980; Van Hartesveldt et al., 1986; Mori et al., 1990; Silver et al., 1993; Marcus and Easter, 1995; Cummings et al., 1997; Fitch and Silver, 1997; Pires-Neto et al., 1998). During the formation of the anterior commissure in mammals, glia develop on either side of the tract, forming a tunnel-like structure as the fibers of the anterior commissure begin to cross the midline (Cummings et al., 1997; Pires-Neto et al., 1998). Their existence and position during anterior commissure formation suggests that these glia may play a role in containing the axons within the tract during development.

In Drosophila, midline glia function as guidepost cells that direct axons to project either ipsilaterally or contralaterally to form midline commissures (Jacobs and Goodman, 1989; Hummel et al., 1999a,b; Kidd et al., 1998a,b, 1999). In vertebrates, roof plate glia in the dorsal midline of the spinal cord prevent growing axons from crossing the midline (Snow et al., 1990) through the actions of bone morphogenetic proteins (Augsburger et al., 1999). In the midline raphe of the midbrain, hindbrain, and cervical spinal cord, an extensive radial glial structure exists both during development and in adulthood (Van Hartesveldt et al., 1986; Mori et al., 1990) called the midline raphe glial structure (MRGS). The glial cells that make up the MRGS label with both an antibody against S-100 protein (Van Hartesveldt et al., 1986) and with the monoclonal antibody R2D5 (Mori et al., 1990) but are not GFAP-positive (Van Hartesveldt et al., 1986). The MRGS forms a continuous band of radial glial fibers separating the right and left brainstem but with some interruptions to allow for the passage of decussating fibers. Its structure suggests that the MRGS may be involved in sorting and organizing ipsilaterally and contralaterally projecting axons during development (Mori et al., 1990), as has been shown to be the function of radial glial at the mammalian optic chiasm (Marcus et al., 1995; Erskine et al., 2000).

An additional function of the glial wedge may be to sort out contralaterally projecting callosal axons from ipsilaterally projecting perforating axons (Hankin and Silver, 1988). The perforating pathway consists of axons extending perpendicular to the corpus callosum (Hankin and Silver, 1988). These ipsilaterally projecting 

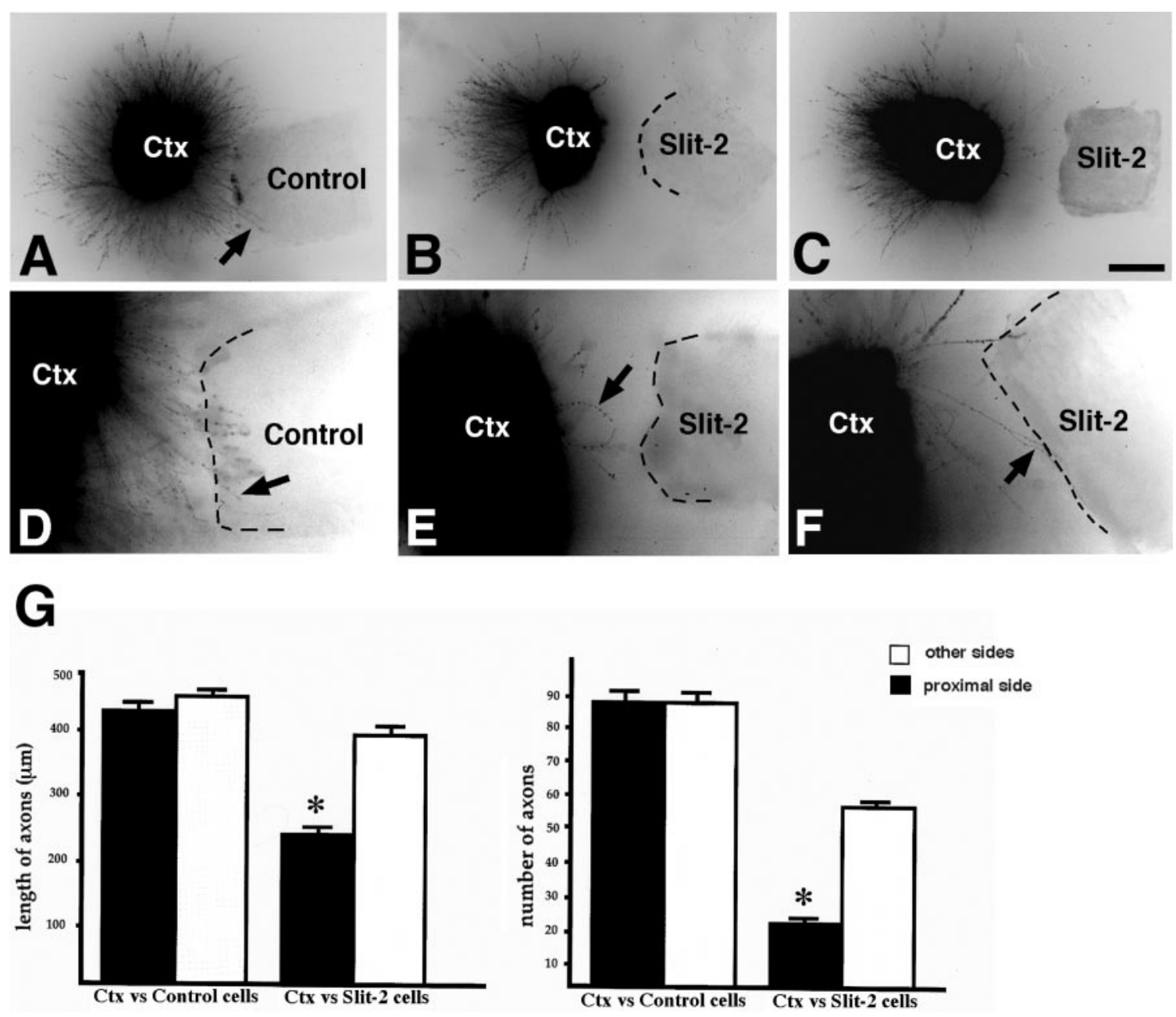

Figure 6. Slit-2 suppresses and repels E17 cortical axons. Cortical explants $(C t x)$ derived from E17 mouse brains were cocultured with $293 \mathrm{~T}$ cells transfected with either a control (vector alone) construct $(A, D ; D$ is a higher power view of $A)$ or a Slit-2 expression construct $(B, C, E, F ; 4$ different examples). Explants were cultured for $3 \mathrm{~d}$ and fixed, and then the cortical explant was injected with DiI to label axonal outgrowth. Cortical explants display a symmetrical growth when cocultured with control transfected cells $(A)$, even growing into the transfected cell block $($ arrow in $D)$. However, when cocultured with Slit-2-expressing cells, cortical axon outgrowth was severely suppressed in the proximal side facing the cell block $(B, C)$, with some axons turning away (arrow in $E$ ) and refusing to enter the cell block (arrow in $F$ ). $G$, Quantification of axonal length (mean axon length was derived by measuring the length of the 10 longest axons on each side of the explant) and number on the proximal side versus the other three sides of the explants. Statistically significant results are labeled (*). Scale bar (in $C$ ): $A-C, 300 \mu \mathrm{m} ; D-F, 150 \mu \mathrm{m}$.

axons are able to cross the sling, projecting medial to the tips of the glial wedge on either side of the midline (our unpublished observation). Presumably, these ipsilaterally projecting axons are guided by different molecular mechanisms than the contralaterally projecting callosal axons.

The long radial processes of the glial wedge resemble those of radial glia (Rakic, 1972) found within the developing cortex. Radial glia have been shown to assist callosal axons after crossing the midline in finding their correct targets in the contralateral cortical plate (Norris and Kalil, 1991), indicating that glia, including radial glia, may be involved in guiding callosal axons along much of their pathway.

The guidance properties of the glial wedge indicate that callosal axons are guided by a short-range diffusible or membranesubstrate-bound molecule. Slit-2 has been shown to act in a similar manner in a number of different assay systems (BaCharvet et al., 1999; Brose et al., 1999; Li et al., 1999). When transfected into cell lines, the Slit-2 molecule is proteolytically cleaved into two fragments: an N-terminal fragment of $140 \mathrm{kDa}$ and a C-terminal fragment of 50-60 kDa (Brose et al., 1999; Wang et al., 1999). Both the N-terminal and full-length molecules remain attached to the cell membrane (and mediate axonal collapse), whereas the C-terminal fragment can diffuse into the media (Brose et al., 1999). Therefore, Slit-2 probably mediates repulsion as a membrane-associated or weakly diff usible molecule in three-dimensional collagen gels. Consistent with this, we observed repulsive influences by the Slit-2-expressing cells when cortical explants were placed $<450 \mu \mathrm{m}$ from the cell blocks, indicating that Slit-2 acts as a short-range guidance molecule identical to the glial wedge guidance activity.

Because callosal axons grow between the glial wedge and the indusium griseum glia, callosal axons may be guided by surround repulsion as has been described for the patterning of sensory axon trajectories from the dorsal root ganglia (Keynes et al., 1997). In this system, axons from neurons in the dorsal root ganglia are channeled into bipolar trajectories when cocultured between explants of notochord and dermomyotome. Slit-2 expression in both the glial wedge and the indusium griseum may provide a surround 


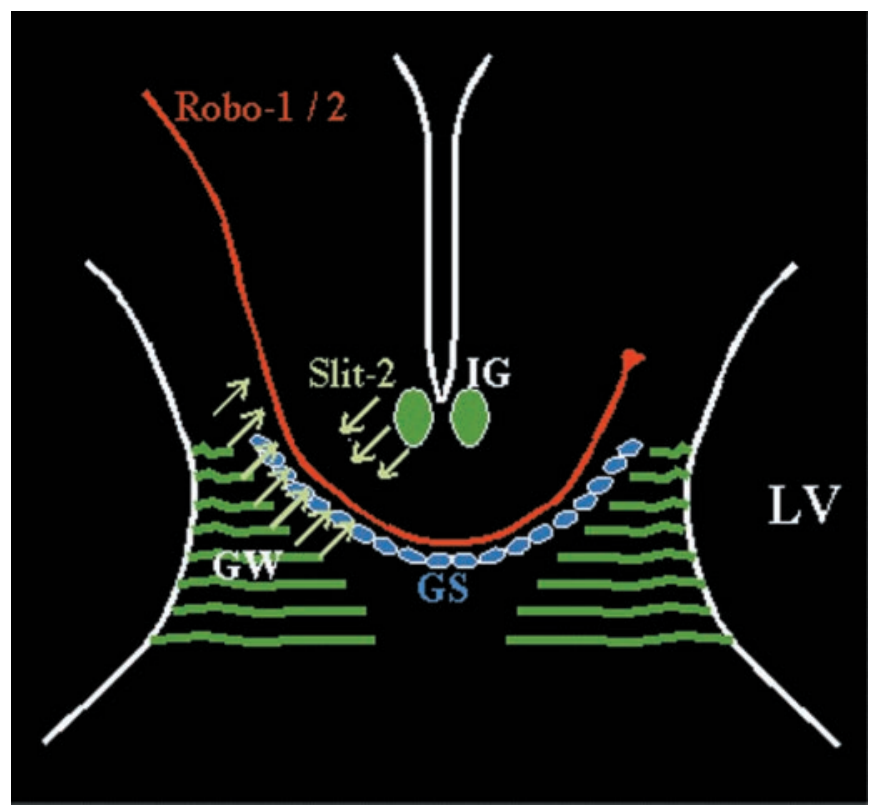

Figure 7. Model of axon guidance across the corpus callosum by midline glial populations. The glial wedge $(G W)$ and the indusium griseum glia $(I G)$ express Slit-2, repelling axons away from these structures. Because slit-2 acts as a short-range guidance cue, callosal axons (shown in red; expressing the slit-2 receptors robo- 1 and robo-2) are not inhibited from approaching the midline but turn when they encounter the glial wedge. Callosal axons may then use positive guidance signals from the glial sling $(G S)$ to cross the midline and may then be deflected dorsally by the glial wedge in the opposite hemisphere. $L V$, Lateral ventricle.

repulsion that defines the pathway of the callosal axons in a similar manner. How callosal axons are then able to leave the midline once they cross the corpus callosum remains to be determined. The results reported here demonstrate that midline glia play a crucial role in the formation of commissures within the mammalian brain.

\section{REFERENCES}

Augsburger A, Schuchardt A, Hoskins S, Dodd J, Butler S (1999) BMPs as mediators of roof plate repulsion of commissural neurons. Neuron 24:127-141.

Ba-Charvet KTN, Brose K, Marillat V, Kidd T, Goodman CS, TessierLavigne M, Sotelo C, Chedotal A (1999) Slit2-Mediated chemorepulsion and collapse of developing forebrain axons. Neuron 22:463-473.

Brenner M, Kisseberth WC, Su Y, Besnard F, Messing A (1994) GFAP promoter directs astrocyte-specific expression in transgenic mice. J Neurosci 14:1030-1037.

Brose K, Bland KS, Wang KH, Arnott D, Henzel W, Goodman CS, Tessier-Lavigne M, Kidd T (1999) Slit proteins bind Robo receptors and have an evolutionarily conserved role in repulsive axon guidance. Cell 96:795-806.

Cummings DM, Malun D, Brunjes PC (1997) Development of the anterior commissure in the opossum: midline extracellular space and glia coincide with early axon decussation. J Neurobiol 32:403-414.

Dahme M, Bartsch U, Martini R, Anliker B, Schachner M, Mantei N (1997) Disruption of the mouse L1 gene leads to malformation of the nervous system. Nat Genet 17:346-349.

Dattani MT, Martinez-Barbera JP, Thomas PQ, Brickman JM, Gupta R, Matensson IL, Toresson H, Fox M, Wales JK, Hindmarsh PC, Krauss S, Beddington RS, Robinson IC (1998) Mutations in the homeobox gene HESX1/Hesx1 associated with septo-optic dysplasia in human and mouse. Nat Genet 19:125-133.

Erskine L, Williams SE, Brose K, Kidd T, Rachel RA, Goodman CS, Tessier-Lavigne M, Mason CA (2000) Retinal ganglion cell axon guidance in the mouse optic chiasm: expression and function of robos and slits. J Neurosci 20:4975-4982.

Fazeli A, Dickinson SL, Hermiston ML, Tighe RV, Steen RG, Small CG, Stoeckli ET, Keino-Masu K, Masu M, Rayburn H, Simons J, Bronson RT, Gordon JI, Tessier-Lavigne M, Weinberg RA (1997) Phenotype of mice lacking functional Deleted in colorectal cancer (DCC) gene. Nature 386:796-804.

Fitch MT, Silver J (1997) Glial cell extracellular matrix: boundaries for axon growth in development and regeneration. Cell Tissue Res 290:379-384.

Goodhill GJ (1997) Diffusion in axon guidance. Eur J Neurosci 9:1414-1421.

Hankin MH, Silver J (1988) Development of intersecting CNS fiber tracts: the corpus callosum and its perforating fiber pathway. J Comp Neurol 272:177-190.

$\mathrm{Hu} \mathrm{H}$ (1999) Chemorepulsion of neuronal migration by Slit2 in the developing mammalian forebrain. Neuron 23:703-711.

Hummel T, Schimmelpfeng K, Klambt C (1999a) Commissure formation in the embryonic CNS of Drosophila. I. Identification of the required gene functions. Dev Biol 209:381-398.

Hummel T, Schimmelpfeng K, Klambt C (1999b) Commissure formation in the embryonic CNS of Drosophila. II. Function of the different midline cells. Development 126:771-779.

Jacobs JR, Goodman CS (1989) Embryonic development of axon pathways in the Drosophila CNS. I. A glial scaffold appears before the first growth cones. J Neurosci 9:2402-2411.

Kennedy TE, Serafini T, De la Torre JR, Tessier-Lavigne M (1994) Netrins are diffusible chemotropic factors for commissural axons in the embryonic spinal cord. Cell 78:425-435.

Keynes R, Tannahill D, Morgenstern DA, Johnson AR, Cook GMW, Pini A (1997) Surround repulsion of spinal sensory axons in higher vertebrate embryos. Neuron 18:889-897.

Kidd T, Brose K, Mitchell KJ, Fetter RD, Tessier-Lavigne M, Goodman CS, Tear G (1998a) Roundabout controls axon crossing of the CNS midline and defines a novel subfamily of evolutionarily conserved guidance receptors. Cell 92:205-215.

Kidd T, Russell C, Goodman CS, Tear G (1998b) Dosage-sensitive and complementary functions of roundabout and commissureless control axon crossing of the CNS midline. Neuron 20:25-33.

Kidd T, Bland KS, Goodman CS (1999) Slit is the midline repellent for the robo receptor in Drosophila. Cell 96:785-794.

Levitt P, Rakic P (1980) Immunoperoxidase localization of glial fibrillary acidic protein in radial glial cells and astrocytes of the developing rhesus monkey brain. J Comp Neurol 193:815-840.

Li H, Chen J, Wu W, Fagaly T, Zhou L, Yuan W, Dupuis S, Jiang Z, Nash W, Gick C, Ornitz DM, Wu JY, Rao Y (1999) Vertebrate slit, a secreted ligand for the transmembrane protein roundabout, is a repellent for olfactory bulb axons. Cell 96:807-818.

Marcus RC, Easter SS (1995) Expression of glial fibrillary acidic protein and its relation to tract formation in embryonic zebrafish (Danio rerio). J Comp Neurol 359:365-381.

Marcus RC, Blazeski R, Godement P, Mason CA (1995) Retinal axon divergence in the optic chiasm: uncrossed axons diverge from crossed axons within a midline glial specialization. J Neurosci 15:3716-3729.

Metin C, Deleglise D, Serafini T, Kennedy TE, Tessier-Lavigne M (1997) A role for netrin-1 in the guidance of cortical efferents. Development 124:5063-5074

Mori K, Ikeda J, Hayaishi O (1990) Monoclonal antibody R2D5 reveals midsagittal radial glial system in postnatally developing and adult brainstem. Proc Natl Acad Sci USA 87:5489-5493.

Niclou SP, Jia L, Raper JA (2000) Slit2 is a repellent for retinal ganglion cell axons. J Neurosci 20:4962-4974.

Norris CR, Kalil K (1991) Guidance of callosal axons by radial glia in the developing cerebral cortex. J Neurosci 11:3481-3492.

Orioli D, Henkenmeyer M, Lemke G, Klein R, Pawson T (1996) Sek4 and Nuk receptors cooperate in guidance of commisural axons and in palate formation. EMBO J 15:6035-6049.

Pires-Neto M, Braga-De-Souza S, Lent R (1998) Molecular tunnels and boundaries for growing axons in the anterior commissure of hamster embryos. J Comp Neurol 399:176-188.

Qiu M, Anderson S, Chen S, Meneses JJ, Hevner R, Kuwana E, Pedersen RA, Rubenstein JLR (1996) Mutation of the Emx-1 homeobox gene disrupts the corpus callosum. Dev Biol 178:174-178.

Rakic P (1972) Mode of cell migration to the superficial layers of fetal monkey neocortex. J Comp Neurol 145:61-84.

Richards LJ, Shu T (2000) Slit-2 is a midline axon guidance cue in the developing cortex. Eur J Neurosci [Suppl 11] 12:178.

Richards LJ, Koester SE, Tuttle R, O'Leary DDM (1997) Directed growth of early cortical axons is influenced by a chemoattractant released from an intermediate target. J Neurosci 17:2445-2458.

Ringstedt T, Braisted JE, Brose K, Kidd, T, Goodman C, Tessier-Lavigne M, O'Leary DM (2000) Slit inhibition of retinal axon growth and its role in retinal axon pathfinding and innervation patterns in the diencephalon. J Neurosci 20:4983-4991.

Rothberg JM, Jacobs JR, Goodman CS, Artavanis-Tsakonas S (1990) Slit: an extracellular protein necessary for development of midline glia and commissural axon pathways contains both EGF and LRR domains. Genes Dev 4:2169-2187.

Sancho-Tello M, Valles S, Montoliu C, Renau-Piqueras J (1995) Devel- 
opmental pattern of GFAP and vimentin gene expression in rat brain and in radial glial cultures. Glia 15:157-166.

Serafini T, Kennedy TE, Galko MJ, Mirzayan C, Jessell TM, TessierLavigne M (1994) The netrins define a family of axon outgrowthpromoting proteins homologous to C. elegans UNC-6. Cell 78:409-424.

Serafini T, Colamaino SA, Leonardo ED, Wang $\mathrm{H}$, Beddington $\mathrm{R}$, Skarnes WC, Tessier-Lavigne M (1996) Netrin-1 is required for commisural axon guidance in the developing vertebrate nervous system. Cell 87:1001-1014.

Shu T, Richards LJ (1999) The glial wedge: a new midline glial population that guides cortical axons across the midline. Soc Neurosci Abstr 25:774.

Shu T, Valentino KM, Seaman C, Cooper HM, Richards LJ (2000) Expression of the netrin-1 receptor, deleted in colorectal cancer (DCC), is largely confined to projecting neurons in the developing forebrain. J Comp Neurol 416:201-212.

Silver J, Ogawa MY (1983) Postnatally induced formation of the corpus callosum in acallosal mice on glia-coated cellulose bridges. Science 220:1067-1069.

Silver J, Lorenz SE, Wahlsten D, Coughlin J (1982) Axonal guidance during development of the great cerebral commissures: descriptive and experimental studies, in vivo, on the role of preformed glial pathways. J Comp Neurol 210:10-29.

Silver J, Edwards MA, Levitt P (1993) Immunocytochemical demonstration of early appearing astroglial structures that form boundaries and pathways along axon tracts in the fetal brain. J Comp Neurol 328:415-436.

Snow DM, Steindler DA, Silver J (1990) Molecular and cellular characterization of the glial roof plate of the spinal cord and optic tectum: a possible role for a proteoglycan in the development of an axon barrier. Dev Biol 138:359-376.
Tear G, Harris R, Sutaria S, Kilomanski K, Goodman CS, Seeger M (1996) Commissureless controls growth cone guidance across the CNS midline in Drosophila and encodes a novel membrane protein. Neuron 16:501-514.

Tuttle R, Nakagawa Y, Johnson JE, O’Leary DDM (1999) Defects in thalamocortical axon pathfinding correlate with altered cell domains in Mash-1 deficient mice. Development 126:1903-1916.

Valentino KL, Jones EG, Kane SA (1983) Expression of GFAP immunoreactivity during development of long fiber tracts in the rat CNS. Brain Res 9:317-336.

Van Hartesveldt C, Moore B, Hartman B (1986) Transient midline raphe glial structure in the developing rat. J Comp Neurol 253:175-184.

Wang KH, Brose K, Arnott D, Kidd T, Goodman CS, Henzel W, Tessier-Lavigne M (1999) Biochemical purification of a mammalian slit protein as a positive regulator of sensory axon elongation and branching. Cell 96:771-784.

Wu W, Wong K, Chen J, Jiang Z, Dupuis S, Wu JY, Rao Y (1999) Directional guidance of neuronal migration in the olfactory system by the protein Slit. Nature 400:331-336.

Yoshida M, Suda Y, Matsuo I, Miyamoto N, Takeda N, Kuratani S, Aizawa S (1997) Emx-1 and Emx-2 functions in development of dorsal telencephalon. Development 124:101-111.

Yuan W, Zhou L, Chen JH, Wu JY, Rao Y, Ornitz DM (1999) The mouse SLIT family: secreted ligands for ROBO expressed in patterns that suggest a role in morphogenesis and axon guidance. Dev Biol 212:290-306

Zhu Y, Li H, Zhou L, Wu JY, Rao Y (1999) Cellular and molecular guidance of GABAergic neuronal migration from an extracortical origin to the neocortex. Neuron 23:473-485. 